\title{
Cultura, política y medios de comunicación. El problema de la determinación
}

institucionales.us.es/ambitos/

\section{Antonio Laguna Platero}

Universidad de Castilla la Mancha

Antonio.Laguna@uclm.es

Descubrir los efectos de los medios en particular y de la comunicación en general sobre las personas define una parte central de las ciencias sociales. Sabemos ya que no se puede explicar el desarrollo histórico -y no solo los grandes acontecimientos-, o los comportamientos políticos o electorales más recientes sin evaluar el papel jugado por la propaganda de antes, comunicación política de ahora. De la misma manera que no es posible concebir el desarrollo del capitalismo sin reconocer

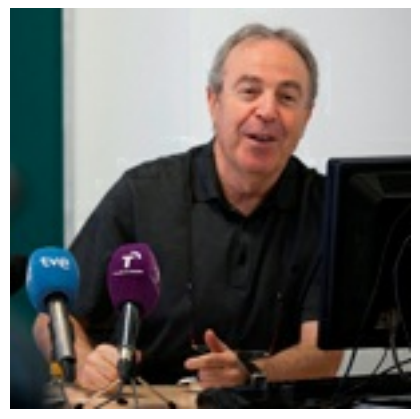
el papel jugado por la publicidad que alimenta el consumo. Es más, el sistema político representativo, centrado en las consultas electorales periódicas, no podría funcionar, al menos teóricamente, sin un sistema comunicativo que permita a los ciudadanos conformar opiniones y expresarlas a través del voto.

El poder y los medios se han alarmado. Es un fenómeno reciente -la pérdida de influencia de los medios "poderosos"- y el mundo será distinto. Desde el siglo XVIII y, sobre todo, desde el XIX y XX los medios de comunicación de masas han sustituido a las iglesias como suministradores

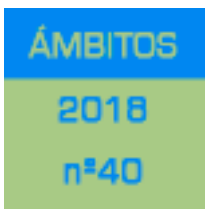
de la narrativa hegemónica. La cultura occidental, sobre todo la anglosajona, tras la llustración, se ha centrado en dos premisas: en la búsqueda de la verdad y en su acceso público (Elías, 2015). Y las dos herramientas que ha usado para ello son la ciencia -el método científico como fórmula de búsqueda- y el periodismo que, con técnicas similares (el proceso de verificación de una noticia se inspira en el método científico), persigue el mismo objetivo. La imprenta fue importante porque democratizó el acceso a los libros (y con ellos el conocimiento), pero también, no lo olvidemos, supuso el nacimiento de la prensa y su influyente papel.

Ambos-método científico y prensa- son creaciones burguesas que han dado un enorme poder y, por qué no decirlo, prosperidad económica, política, tecnológica y cultural a Occidente sobre otros pueblos y culturas del planeta(Jacob, 1988). China inventó la imprenta y el papel; pero no el método científico ni el periodismo (que son europeos); y, por ello, perdió hegemonía desde el XVIII. Si ahora la ha recuperado es porque ha sido consciente del papel de la ciencia (es la segunda productora del mundo) aunque, todo hay que decirlo, no del periodismo.

La verdad, o la búsqueda de la verdad, es algo fundamental para el liberalismo burgués porque permite tener información basada en datos extraídos mediante procesos lógicos con la que realizar elecciones en un entorno -el liberal- donde,supuestamente, el valor 
máximo es la libertad del individuo. Esa libertad lleva la "condena" de tener que tomar constantemente decisiones y, para ello, hace falta información fidedigna: desde qué terapia o medicamento comprar para una enfermedad hasta qué partido votar o qué champú adquirir.

Pero todo ha cambiado con el acceso masivo y gratuito a internet donde todos podemos producir contenidos. Hasta finales del XX, esos contenidos (que son parte de la narrativa dominante) solo eran suministrados por los periodistas o las élites culturales o académicas. $Y$, en general, intentaban seguir el patrón ilustrado de búsqueda y publicación de la verdad. En esta segunda década del XXI la verdad ya no es tan relevante porque importan más los seguidores o las entradas que el prestigio de la fuente o del profesional que firma. Los algoritmos que controlan la comunicación son más cuantitativos (porque son fórmulas matemáticas) que cualitativos. E igual que el liberalismo burgués acabó con el "honor caballeresco" del feudalismo; ahora se ha esfumado el "honor profesional" al que Weber atribuyó un papel fundamental para explicar el capitalismo en su obraLa ética protestante y el espíritu del capitalismo.

En los últimos años han aparecido portales de intoxicación informativa a partir de bulos (o en inglés fakenews) y éstos y su difusión por las redes sociales se han convertido en un arma que, al incidir en procesos electorales en países democráticos, puede dejar vulnerables a naciones con este tipo de mecanismos de participación ciudadana ( $\mathrm{y}$, además, muy conectadas a internet) frente a los países que no los tienen. Es decir, puede ser un "virus" que se inocula mejor en democracias tecnológicas que en dictaduras.

En 2017 el Diccionario Oxford consideró fakenews como palabra del año. Se consignó que su empleo aumentó un 365\%. En diciembre de 2017, en España, el Consejo de Ministros aprobó la "Nueva Estrategia de Seguridad Nacional" que implicaba analizar "campañas de desinformación" y que propuso la creación de una comisión de expertos y editores de medios. Y en enero de 2018 el presidente Macron anunció, durante su discurso sobre los tradicionales "deseos para la prensa", que Francia tendrá también una ley contra las noticias falsas.

El cambio comenzó en 2016 Alemania. La Unión Demócrata Cristiana (CDU) sufrió una dura derrota y su presidenta, Angela Merkel, pronunció una frase que definiría la era: "Últimamente -dijo- vivimos tiempos postfactuales. Ello significa que la gente ya no se interesa por los hechos, sino por los sentimientos (Schaarschidt, 2017)". El término "postfactual" adquirió tal relevancia, tras la reflexión de Merkel, que la Sociedad de la Lengua Alemana lo eligió por unanimidad palabra del año en 2016. Y también en 2016 el diccionario Oxford seleccionó el enfoque anglosajón de postfactual, que sería post-truth (posverdad), como palabra del año.

Lo que está sucediendo es que los medios de comunicación tradicionales pierden influencia en su papel de alimentar connarrativas hegemónicas (narrativas que no dejan de ser paradigmas culturales -desde la religión o la mitología al derecho o la literatura-)a la opinión pública. Éstaqueda liberada de ese paradigmadominante y no rige "la espiral del silencio" de Noelle Neumann. Reaparecen condicionantes biológicos (más primitivos) que estaban escondidos tras el barniz cultural o la presión de narrativas hegemónicas. La cultura floreció hace apenas 5.000 años, frente a los aproximadamente 200.000 años que 
tiene el humano moderno -homo sapiens sapiens-. Es decir, la biología aún es poderosa. Este comportamiento, fundamentado en la bioquímica, es competitivo con el barniz cultural que otorga la civilización -familia, educación y medios de comunicación- y se explica muy biendesde la psicología social y la psicobiología (Schaarschidt, 2017). Este enfoque nos dice que el cerebro (debido a su evolución biológica) no busca necesariamente la verdad sino su bienestar; es decir: el placer y la ausencia de dolor.

Así se explica el "sesgo de confirmación" o "recolección selectiva de evidencias": tendemos a seleccionar información de manera que satisfaga nuestras propias expectativas y, sobre todo, que refuerce nuestra opinión previa (Zollo et al., 2015). Y ello es así porque cuando eso sucede el cerebro segrega una sustancia química, la dopamina, que es un neurotransmisor que también aparece en momentos de placer. Es decir, leer o escuchar algo que confirma nuestra creencia previa, nos causa placer; pero cuando se la refuta, nos produce dolor (y se ha evidenciado que se activan zonas cerebrales que también lo hacen con el dolor). Y, no lo olvidemos, el cerebro está diseñado, biológicamente, para evitar el dolor.

Cuando la narrativa es hegemónica, y no tenemos mecanismos para acceder a otras (como ha sucedido primero con la iglesia o, después, en la era del dominio de medios influyentes) ésa es la que creemos. La disidencia -desde Sócrates a Galileo o Turing- se castiga (Elías, 2105). A los medios influyentes se les puede acusar de errores, pero también han ayudado a mejorar la sociedad en muchos aspectos y, pese a todo, aún mantienen cierta influencia (Quian y Elías, 2018). Es cierto que no han acabado con el capitalismo como a algunos les gustaría (entre otros motivos porque los medios son un subproducto del capitalismo), pero han contribuido mucho a la lucha por los derechos civiles: es inconcebible hoy en día que un gran medio apoye el racismo, la esclavitud o el machismo; aunque, sin embargo, cada día hay más webs "alternativas" que sí los amparan.Eso explica el ascenso de la ultraderecha: su mensaje es contra-hegemónico al de los medios "influyentes", pero no en la red donde se forman "cajas de resonancia (Bessi, 2015)" en las que se repite el mismo tipo de enfoques hasta que sus receptores creen que "esa es la realidad". De ahí que tampoco acierten las encuestas, porque no penetran en esos "guetos mediáticos".

Influye también la denominada "paradoja del conspiranoico", según la cual "aquellos que dicen estar más atentos a la 'manipulación' perpetrada por los medios tienden a interaccionar más a menudo con fuentes de información intencionalmente falsa y, por tanto, son a su vez más proclives a ser manipulados (Quattrociochi, 2016)". Cuando la opinión pública no se informa por los medios, sino por las redes sociales,las "cajas de resonancia" de los conspiranoicos, donde solo interactuamos o elogiamos lo que está de acuerdo con nuestra ideología, configura nuestra narrativa.

Internet pone a nuestro alcance millones de narrativas en competición (antivacunas, teorías de conspiración reptilianas, magia, supremacismo étnico o cultural, etc.). Optar por unas $u$ otras depende de entornos sociales, mediáticos o culturales que nos nutran de narrativas; pero en ausencia de éstas, pueden imponerse instintos primarios (más biológicos) que se ven reforzados por "cajas de resonancia" donde cada instinto busca acomodo. En palabras de Noam Chomsky: "la gente ya no cree en los hechos (Chomsky, 2018)"; y, en su opinión, Trump, que ha ganado gracias a las redes sociales, "representa 
un peligro grave. Ha liberado consciente o deliberadamente olas de racismo, xenofobia o sexismo que estaban latentes pero que nadie había legitimado(Chomsky, 2018)". La solidaridad o la tolerancia, por ejemplo, son conceptos culturales que necesitan ser constantemente estimulados con narrativas poderosas y hegemónicas.

Además del sesgo de confirmación, existe otra variante, el "sesgo partidista", que puede definirse como una desviación cognitiva a favor del propio partido o grupo de referencia al que pertenecemos (Nyhan et al., 2010); es decir, las personas consideran que las afirmaciones contradictorias de su candidato político (o a quien consideren su líder ideológico) son menos graves que las de su adversario. Y esto también lo hace nuestro cerebro (evolucionado de un pasado tribal o de manadas) para adaptarse a entornos hostiles.

A todo esto se añade el "razonamiento motivado", por el cual valoramos la nueva información que recibimos minimizando las emociones negativas y magnificando las positivas (pura supervivencia biológica) y, por último, el denominado "efecto contraproducente" (Van der Linden et al, 2017); por el cual el intento de refutar las creencias erróneas de una persona mediante hechos y datos puede provocar el efecto contrario: defenderá su opinión con mayor vehemencia (esto se ha demostrado entre los grupos antivacunas o los negacionistas del cambio climático, pero también la campaña de The Washington Post para desenmascarar con hechos y datos las mentiras de Trump solo ha producido más adhesión entre sus partidarios).

Estos son los cuatro parámetros que manejan los comunicadores (que no periodistas) del siglo XXI. Sin embargo, el periodismo, como la ciencia, sí que tiene la misión de buscar la verdad y hacerla pública; de ahí que cause dolor y hasta rechazo social (especialmente en posiciones políticas extremas). Para entender la comunicación del siglo XXI es importante resaltar el hecho de que la opinión pública no busca la verdad, sino aquello que confirme sus creencias previas y, en este sentido, tanto Google como Wikipedia, con su declarada "neutralidad", se han convertido en verdaderos campos de batalla ideológicos donde las diferentes tribus mediáticas van configurando su espacio (Elías, 2015). Éstas se alimentan de lo que Damian Thompson, en su libro Los nuevos charlatanes(Thompson, 2009), denomina contraconocimiento y que desemboca en una pandemia de credulidad: "Ideas que en su forma original y bruta florecieron únicamente en los arrabales de la sociedad hoy las consideran en serio incluso personas cultas en el mundo occidental", señala Thompson.La complejidad del tema, la interdisciplinariedad que exige y la multiplicidad de factores que intervienen ha provocado, no solo una diversidad de perspectivas sino una fragmentación de los análisis. Así, desde la historia hemos insistido en los contextos socioeconómicos para explicar la aparición de medios con uno u otro sesgo. Desde la Psicología nos han aportado serias e importantes explicaciones sobre los distintos tipos de efectos que se derivan según la modalidad del mensaje. Desde la Teoría de la Comunicación hemos ido conociendo distintas interpretaciones sobre los tipos, grados y niveles de efectos de los medios según su evolución. La lingüística ha sido básica para conocer la construcción del discurso y las consecuencias mentales que se derivan del uso de las palabras. Incluso desde la Ciencia Política se ha relacionado el compromiso político con la comunicación política recibida. 
fenómeno comunicativo con un esquema jerárquico de interrelaciones se ha producido desde los estudios culturales. Especialmente la Escuela de Birmingham (Centre for Contemporary Cultural Studies), donde nos encontramos con la obra de Raymond Williams y su planteamiento de identificar cultura como "prácticas significativas" que explicarían los modos de vivir y de sentir vida (Williams, 2001). De aquí que, E. P. Thompson reconstruya la historia de la clase obrera, no solo como una formación social, sino también cultural (Storey, 2002: 80 y ss.)

Siguiendo esta propuesta y ligado al estudio de la comunicación política, hace algún tiempo que planteamos la importancia de conocer las culturas políticas de los ciudadanos para evaluar sus consumos comunicativos o sus preferencias electorales (Laguna, 2010). Desde nuestro punto de vista, toda estrategia comunicativa tiene un destinatario que es finalmente quien dicta sentencia. Es el pueblo, en términos tradicionales de discurso democrático, quien tiene la última palabra. De sus características sociales, de su historia colectiva, de sus creencias y actitudes, de los valores que les permiten procesar la información que reciben del mundo de la política, en definitiva, de su cultura política depende en buena medida el color y sentido que tenga dicha elección (Almond y Verba, 1989:12-13). Tal y como recuerdan Anduiza y Bosch, "el individuo compara la información que le llega con algún valor político que tiene interiorizado, intuye si le cuadra o no con este valor político y adopta una postura de aceptación o rechazo de esta información" (Anduiza y Bosch, 2004:189). Por tanto, lo que los individuos votan no sólo dependería de las condiciones materiales en que producen su existencia, o de la dieta informativa que consumen, sino especialmente de los valores que definen sus actitudes sociales y políticas y que adquieren por distintas vías en los procesos de socialización (Lucas Marín, 1982: 82-83).

También podemos evaluar otros condicionantes, enfatizando cómo las desigualdades del mercado se han trasladado a la competencia política o cómo los valores transmitidos por las grandes industrias culturales, desde el cine a la misma publicidad, favorecen a unos frente a otros al ir forjando una cultura política de valores más conservadores, de información más simplificada o de actitudes cada vez más cínicas y alejadas de lo político. A partir de ahí podemos subrayar el impacto que sobre la política y lo político ha generado el dominio del mercado que impregna todos los ámbitos del pensamiento y de la cultura en los últimos años. Pongamos un ejemplo preciso: defender lo colectivo y lo público, frente al avance del individualismo y de lo privado que ofrece buena parte de las industrias culturales, constituye ya de por sí una desventaja de partida importante para cualquier propuesta política. La cultura mediática difunde un modelo conservador que, de partida, choca ya con el discurso progresista, al menos en la consolidación de los marcos mentales profundos que ha expuesto Lakoff (2007: 110).

La clave final, por tanto, es la receptividad y predisposición de los ciudadanos, lo que conecta directamente con el concepto de cultura política como rasgo global que identifica los tipos de públicos. Significa reconocer que la cultura política da sentido a las acciones y roles desempeñados por el individuo, "siendo la gran mediadora entre el medio ambiente y el grupo social, pues las normas y valores culturales aceptados pueden ser considerados como elementos importantes para el mantenimiento del orden social entre individuos físicamente diferentes (Muñoz, 1989: 17). Tales orientaciones individuales incluyen 
diversos componentes: "a) orientaciones cognitivas, conocimiento preciso -o no- de los objetos políticos y de las creencias; b) orientaciones afectivas, sentimientos de apego, compromisos, rechazos y otros similares respecto de los objetos políticos, y c) orientaciones evaluativas, juicios y opiniones sobre los aspectos políticos que, por lo general, suponen la aplicación de determinados criterios de evaluación a los objetos y acontecimientos políticos" (Almond y Powell, 1972: 50).

A partir de esta perspectiva se colige la panoplia enorme y compleja de fenómenos que conforman el concepto de cultura política. Hasta tal punto que cualquier aproximación requiere del estudio, tanto de los procesos históricos y de las dinámicas sociales que han configurado el desarrollo social, pasando por el diagnóstico acerca de cómo se han configurado las estructuras socioeconómicas, así como del estudio de las vías de socialización que, como la familia, la escuela o los medios de comunicación, posibilitan la integración funcional del individuo en la comunidad. De acuerdo con esta amplitud de campos se puede clasificar en tres dimensiones analíticas:

"la cultura como comunicación (es decir, como conjunto de sistemas de símbolos, signos, emblemas y señales, entre los que se incluyen no sólo la lengua, sino también el hábitat, la alimentación, el vestido, etc.;

la cultura como stock de conocimientos (no sólo la ciencia, sino también otros modos de conocimiento como las creencias y el conocimiento práctico del sentido común);

y la cultura como visión del mundo (que incluye las religiones, las filosofías, las ideologías $\mathrm{y}$, en general, toda reflexión sobre "totalidades" que implican un sistema de valores y, por lo mismo, dan sentido a la acción y permiten interpretar el mundo". (Giménez, 2007: 110).

La pregunta final es que medio determina la cultura política del individuo. Para unos, sigue siendo la socialización primaria, la que se produce entre la familia y los iguales la que imprime una huella que determina las actitudes posteriores. Para otros, siquiera sea por la cantidad de horas que los consumimos, la supremacía la ejercen los medios masivos de comunicación. Tal y como destaca P. Bourdieu, las formas de ver, entender y opinar acerca del mundo han quedado moldeadas por el lenguaje audiovisual, por las rutinas productivas de los medios, por los valores noticia que provoca la selección de contenidos y, sobre todo, por la lógica económica que rige los destinos empresariales propietarios del medio, el "plebiscito comercial" que plantea el sociólogo francés (Bourdieu, 1996). Desde este otro punto de vista, "la cultura política del público estará acotada por la realidad política televisada a la que acceden los ciudadanos" (Jerez, Sampedro y Baer, 2000: 19). Incluso hay quien le ha puesto nombre a este efecto, "videopolítica", la ha llamado G. Sartori, en su polémico ensayo sobre el nuevo "homo videns" que nace de la cultura audiovisual. Un nuevo ciudadano en el que el hecho de ver sustituye al de entender y el mundo sensible al inteligible. La televisión ha matado al "homo sapiens", poseedor del lenguaje abstracto fundado en la lógica, de un pensamiento conceptual y de un conocimiento analítico-científico (Sartori, 1998: 45 y ss.; Sánchez Noriega, 2002: 293).

\section{Bibliografía Citada}

ALMOND, G. y POWELL G.B. (1972): Política comparada. Buenos Aires: Paidós. 
ALMOND, G. y VERBA, S. (1970): La Cultura Cívica. Estudio sobre la participación política democrática en Cinco Naciones. Madrid: Fundación de Fomento de estudios Sociales y de Sociología Aplicada.

ANDUIZA, E. y BOSCH, A. (2004): Comportamiento político y electoral. Barcelona: Ariel Ciencia Política.

BOURDIEU, P. (1996): Sobre la televisión. Barcelona: Anagrama.

GIMENEZ, G. (2007): Estudios sobre la cultura y las identidades sociales. México: Conaculta-Iteso.

JEREZ, A., SAMPEDRO, V. y BAER, A. (2000): Medios de comunicación, consumo informativo y actitudes políticas en España. Madrid: CIS.

MUNOZ, B. (1989): Cultura y comunicación: Introducción a las teorías contemporáneas. Barcelona: Barcanova. Temas Universitarios.

LAKOFF, G.(2007): No pienses en un elefante. Lenguaje y debate político. Madrid: Foro Complutense.

LAGUNA, A. (2010): Las claves del éxito político. ¿Por qué votan los ciudadanos? Barcelona: Península.

LUCAS MARÍN, A. (1982): Introducción a la sociología. Capítulo "Conceptos básicos en Sociología". Pamplona: Editorial ELINSA.

SÁNCHEZ NORIEGA, J.L. (2002): Crítica de la seducción mediática. Comunicación y cultura de masas en la opulencia informativa. Madrid: Técnos.

SARTORI, G. (1998): Homo Videns. La Sociedad teledirigida. Madrid: Taurus Pensamiento.

STOREY, John (2002): Teoría cultural y cultura popular. Barcelona: Octaedro-EUB. WILLIAMS, R. (2001): Cultura y sociedad, 1780-1950. De Coleridge a Orwell. Buenos Aires: Nueva Visión.

\section{BREVE SEMBLANZA DEL AUTOR:}

Antonio Laguna Platero es profesor titular de Periodismo en la Universidad de Castilla la Mancha. Sus líneas de investigación se han dividido entre la historia de la comunicación y del periodismo y la comunicación política, siendo autor de más de un centenar de trabajos. Ha sido director de comunicación de diversas organizaciones y decano de la Facultad de Periodismo de la UCLM.

Ámbitos. Revista Internacional de Comunicación, n.40, edición de primavera, 2018. 